\title{
Thomson Scattering Diagnostic on the ETE Tokamak: Status and Progress
}

\author{
L. A. Berni, E. Del Bosco, R. M. Oliveira, and M. P. Alonso* \\ Instituto Nacional de Pesquisas Espaciais (INPE), Laboratório Associado de Plasma (LAP), \\ 12.227-010 São José dos Campos - SP, Brazil \\ *Associação EURATOM/IST, Centro de Fusão Nuclear, 1049-001, Lisboa, Portugal
}

Received on 8 December, 2003; revised version received on 30 April, 2004

\begin{abstract}
In order to measure the plasma temperature and density in the spherical tokamak ETE, a one-channel Thomson scattering system was implemented. During the upgrade of capacitor banks and optimization since the beginning of operation, the plasma pulse duration has increased from $1.5 \mathrm{~ms}$ up to $12 \mathrm{~ms}$ with plasma currents varying from $10 \mathrm{kA}$ to $60 \mathrm{kA}$. During this phase, the electron temperature was increased from $20 \mathrm{eV}$ to 160 $\mathrm{eV}$ with densities as high as $3.5 \times 10^{19} \mathrm{~m}^{-3}$. Presently, the Thomson scattering diagnostic is being upgraded based on the time-delay technique, that consists in using fibers of different lengths to transmit the scattered light signals to the same polychromator. This system will allow measurements of electron temperature and density profiles with ten spatial points per laser shot and per polychromator. This work describes in details the Thomson scattering system, presents a selection of results obtained by this system since the initial phase of operation, and shows details of the proposed upgrade of the Thomson scattering system.
\end{abstract}

\section{The ETE Spherical Tokamak}

The ETE (Experimento Tokamak Esférico) is a medium-size spherical torus with an aspect ratio of 1.5 , major radius of $0.3 \mathrm{~m}$, toroidal field of $0.4 \mathrm{~T}$ and plasma current of $0.22 \mathrm{MA}$ for the first stage of operation [1]. The objectives of the project are focused on plasma edge investigation, development of diagnostics and training on tokamak operation.

The vacuum vessel was manufactured with Inconel 625 with an external diameter and height of $1.2 \mathrm{~m}$ and an internal tube with a diameter of $0.18 \mathrm{~m}$, which houses the ohmic solenoid and the inner legs of the toroidal coils. Good access for diagnostics is provided by 58 Conflat ports (12xCF14", $4 \times C F 250$ and $42 \times C F 40)$. The vacuum system comprises three pumps: one turbo drag pump $(1500 \mathrm{l} / \mathrm{s})$ backed by an oilfree diaphragm $\left(4 \mathrm{~m}^{3} / \mathrm{h}\right)$ and an auxiliary mechanical pump $\left(30 \mathrm{~m}^{3} / \mathrm{h}\right)$. A base pressure of $7.8 \times 10^{-8}$ Torr was achieved after conditioning the vessel walls with baking $\left(\mathrm{T}<150{ }^{\circ} \mathrm{C}\right)$ and DC glow discharge cleaning (GDC) with helium gas.

There are three capacitor banks that storage energy for the toroidal, ohmic heating and equilibrium coils. The energy of the capacitor banks is being increased by adding more capacitors and increasing the maximum voltage rating. Presently, the acquisition system is based on CAMAC and oscilloscopes that, in a near future, will be replaced by VME technology [2].

Table 1 summarizes the status of the proposed diagnostics for ETE. For this initial phase a set of electromagnetic and optical diagnostics are already installed. For edge plasma investigation a $10 \mathrm{keV}$ Fast Neutral Lithium Beam (FNLB) is under development with glassy $\beta$-eucryptite source that will furnish beam currents up to $1 \mathrm{~mA} / \mathrm{cm}^{2}$ [3]. To measure the electron temperature and density profiles a one-channel Thomson scattering (TS) system was implemented.

\section{Thomson Scattering Diagnostic in ETE}

The TS is based on a $10 \mathrm{~J}$ Q-switched ruby laser $(\lambda=694.3$ $\mathrm{nm}$, pulse duration: $30 \mathrm{~ns}$ ) that probes the plasma horizontally at the mid-plane. The laser beam path is adjusted by three mirrors (M1, 2 and 3) and a lens (L3) of $\mathrm{f}=3 \mathrm{~m}$ focuses the beam at the plasma center. A beam expander (L1 and 2) increases the beam diameter from $2 \mathrm{~cm}$ to $3 \mathrm{~cm}$ to keep the energy density below the threshold limit of the optical components. A photodiode $(\mathrm{P})$ was placed behind the mirror M1 for monitoring the laser beam energy during the shots. The laser beam enters the vacuum vessel through a window (W) connected to the vessel by a flight line of 1.7 $\mathrm{m}$ long. A schematic drawing of the present TS system is showed in Fig. 1. Recently, the length of the flight line was increased by $40 \mathrm{~cm}$ and the black anodized aluminum inserts were replaced by stainless steel sheets with high temperature black painting. One aperture of $2.5 \mathrm{~cm}$ was placed inside the tube after the entrance window (W) and one of $2.0 \mathrm{~cm}$ at the end. Eight more apertures of $4.0 \mathrm{~cm}$ were distributed along the tube. The laser beam is stopped by two graphite plates housed inside the dump assembly. To reduce the stray light these plates present special design and their relative position can be adjusted through a linear vacuum feed-through. Presently, the distance from the dump to the vessel is $65 \mathrm{~cm}$, $12 \mathrm{~cm}$ more than the previous setup. The changes described above decreased the stray light level by a factor of 10 reducing the errors on the measurements, and removal of the 
TABLE 1: Status of the proposed diagnostics for ETE.

\begin{tabular}{|c|c|c|}
\hline Diagnostic & Status & Parameters \\
\hline 1 Residual gas analyzer & Installed & Vacuum vessel conditioning \\
\hline 3 Rogowski coils & Installed & $\begin{array}{l}\text { Toroidal, equilibrium and } \\
\text { ohmic currents }\end{array}$ \\
\hline $\begin{array}{l}2 \text { Rogowski coils (one inside the } \\
\text { vessel) }\end{array}$ & Installed & $\begin{array}{l}\text { Plasma and induced vessel } \\
\text { currents }\end{array}$ \\
\hline $\begin{array}{l}12 \text { Loop voltage coils (one inside the } \\
\text { vessel) }\end{array}$ & Installed & $\begin{array}{l}\text { Induced voltage and magnetic } \\
\text { flux }\end{array}$ \\
\hline $\begin{array}{l}4 \mathrm{~B}_{z} / \mathrm{B}_{r} \text { magnetic pick up coils } \\
\text { (protected by the graphite limiter) }\end{array}$ & Installed & MHD and magnetic field \\
\hline $\begin{array}{l}2\left(\mathrm{~B}_{z}, \mathrm{~B}_{r} \text { and } \mathrm{B}_{T}\right) \text { movable magnetic } \\
\text { pick up coils (at the mid-plane) }\end{array}$ & Installed & MHD and magnetic field \\
\hline $\begin{array}{l}1 \text { Movable electrostatic probe (at the } \\
\text { mid-plane) }\end{array}$ & Installed & Edge plasma \\
\hline $\begin{array}{l}\text { 1 H-alpha detector with interference } \\
\text { filter }(\Delta \lambda=13.52 \mathrm{~nm})\end{array}$ & Installed & H-alpha line behavior \\
\hline 1 Visible light spectrometer $(12 \AA / \mathrm{mm})$ & Installed & Impurity emission \\
\hline $\begin{array}{l}1 \text { CCD camera }(500 \text { FPS and shutter } \\
\text { speed up to } 1 / 10,000)\end{array}$ & $\begin{array}{l}\text { Installed } \\
\text { (By loan) }\end{array}$ & Optical imaging \\
\hline 1 Hard x-ray detector & Installed & Fast electrons \\
\hline 1 Thomson scattering system & Installed & $\begin{array}{l}\text { Electron temperature and } \\
\text { density profiles }\end{array}$ \\
\hline 1 Fast lithium beam probe & Installed & Edge plasma \\
\hline $1 \mathrm{CO}_{2}$ laser interferometer & Planned & Integrated density \\
\hline Soft x-ray array & Planned & Electron temperature imaging \\
\hline Electrostatic probes array & Planned & Edge plasma \\
\hline Bolometers & Planned & Radiated power \\
\hline
\end{tabular}

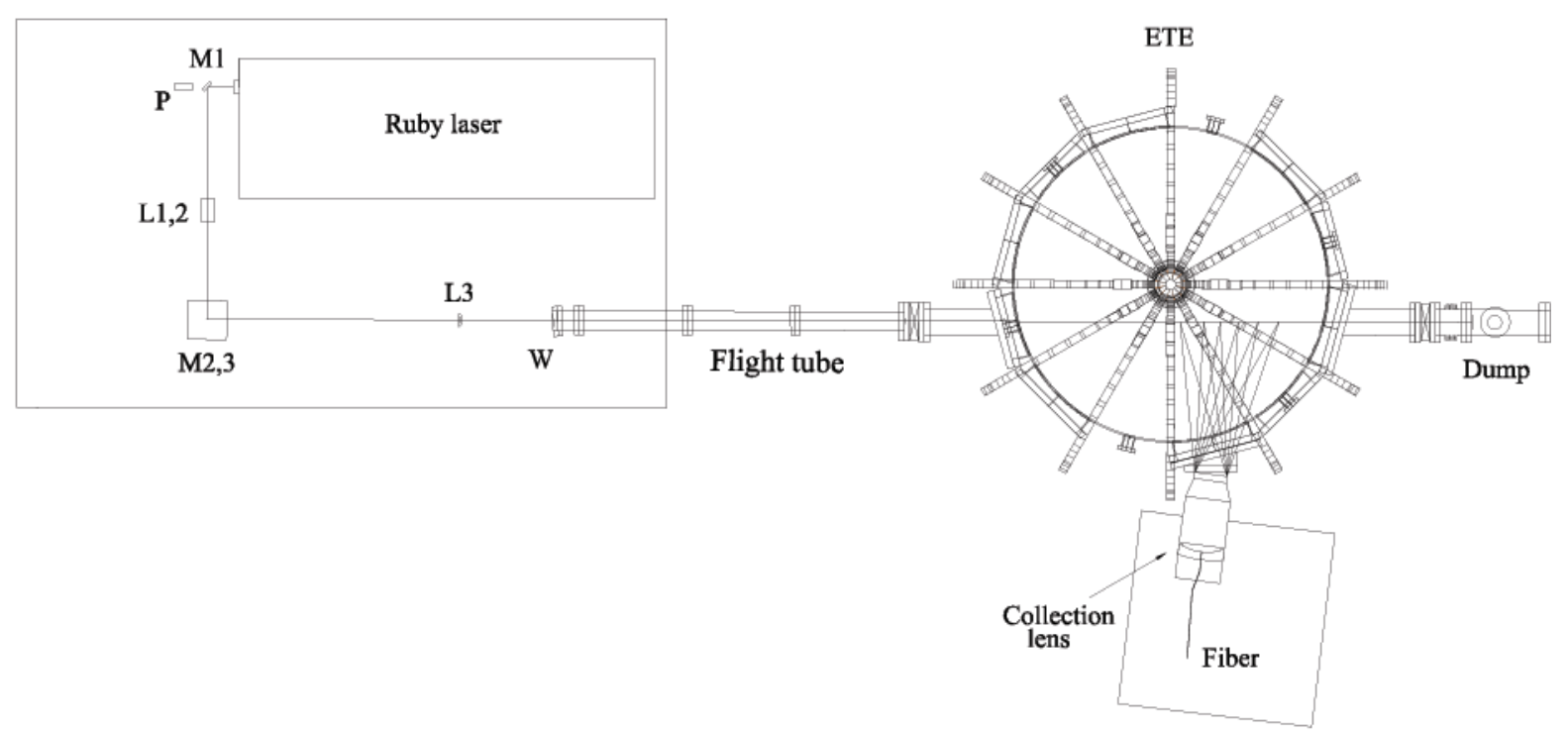

Figure 1. Schematic diagram of the ETE Thomson scatteringsystem. M1,2,3: flat mirrors; P: photodiode; L1,2: beam expander lenses; L3:focusing lens; W: entrance window. 
aluminum parts allowed a better vacuum vessel conditioning. An f/6.3 lens images the scattered light on a $7 \mathrm{~m}$ long fiber bundle with effective cross-section of $4.5 \times 1.5 \mathrm{~mm}^{2}$ that is spectrally analyzed by a 5-channel filter polychromator. The present TS diagnostic was optimized to measure temperatures in the range of 20 to $2000 \mathrm{eV}$ and densities greater than $1 \times 10^{19} \mathrm{~m}^{-3}$ along $50 \mathrm{~cm}$ inside the plasma with a resolution of $15 \mathrm{~mm}$ (shot by shot) [4]. For density measurements the TS was calibrated by rotational Raman scattering with nitrogen gas at pressures between 10 and 100 Torr.

\section{Thomson Scattering Results in ETE}

Figure 2 presents typical signals showing the evolution of the plasma current profile of ETE discharges until the last campaign of 2002. The first plasma was achieved at the end of 2000 with currents up to $12 \mathrm{kA}$ and pulse duration of about $1.5 \mathrm{~ms}$. The five profiles are representative of different phases of operation.

Figure 3 shows a collection of temperature values determined by TS for different times in several discharges similar to shot \#1881 (Fig. 2). Plasma currents of $25 \mathrm{kA}$ lasting for $3.5 \mathrm{~ms}$ were achieved after the introduction of a new pair of ohmic heating coil in series with the existing ones, which reduced the stray field level. The maximum measured temperature was less than $40 \mathrm{eV}$ for a radial position of $30 \mathrm{~cm}$. Due to the high stray light level of the initial TS setup the measurements were restricted to $\mathrm{R}=30 \mathrm{~cm}$. As described in the previous section, modifications in the optical path of the laser beam and in the internal geometry of the dump reduced the stray light level in the TS system for shots starting from \#2230.

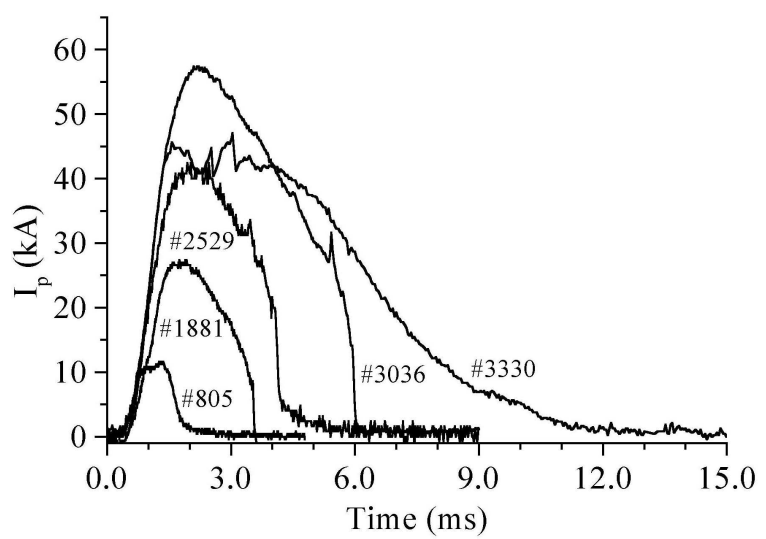

Figure 2. ETE plasma evolution: \#805 (28/11/2000): First plasma, \#1881 (20/11/2001): After the ohmic heating improvements, \#2529 (25/03/2002): After the external parameters optimization, \#3036 (25/11/2002): After the toroidal and ohmic banks upgrade, \#3330 (27/12/2002): After the glow discharge cleaning.

By optimizing the time delays, the voltage rating of the capacitor banks, the working gas parameters and by the vacuum vessel conditioning due to the cleaning effect of the repetitive discharges, the plasma current reached up to 40 kA with typical time profile as shown in shot \# 2529 (Fig. 2). Fig. 4 shows a set of diagnostics results including electron temperature and density profiles for these discharges. From the temporal sequence of TS measurements (Figs. 4A and 4B) it can be observed that the plasma column compresses towards the central column achieving temperatures up to $160 \mathrm{eV}$ and densities of $2.2 \times 10^{19} \mathrm{~m}^{-3}$. This shift of the plasma column to the position near $\mathrm{R}=22 \mathrm{~cm}$ can be associated to high values of the vertical magnetic field necessary to compensate for the stray fields. The magnetic $\mathrm{B}_{z}$ probe (Fig. 4C) placed at the mid-plane behind the graphite limiter of the vessel central column confirms the plasma shift as its signal increases during the discharge.

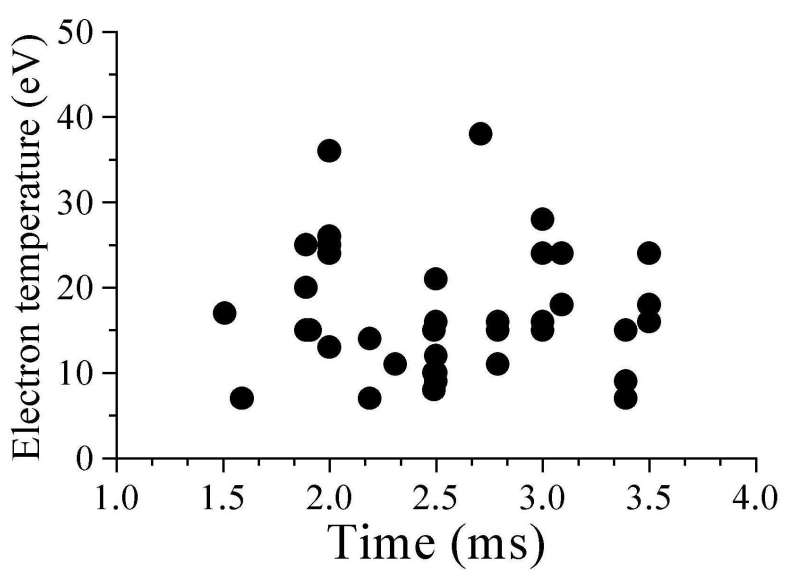

Figure 3. First electron temperature measurements (shots \#1846 to \#2057) with TS diagnostic $(\mathrm{R}=30 \mathrm{~cm})$ during the ETE discharge profiles as shot \#1881 (see Fig. 2).

The plasma behavior represented by shot \#3036 was obtained after increasing the energy of the toroidal and ohmic heating capacitor banks. Presently, the available energy of the banks are $300 \mathrm{~kJ}$ for the toroidal, $270 \mathrm{~kJ}$ for the ohmic heating and $27 \mathrm{~kJ}$ for the equilibrium. These values represent approximately $1 / 4$ of the total energy expected for the initial stage of operation (Ip $\approx 200 \mathrm{kA}$ ). Fig. 5 (A and B) present $\mathrm{T}_{e}$ and $\mathrm{n}_{e}$ signals at $4.5 \mathrm{~ms}$ after the breakdown of the plasma. The results show that the density increased up to $3.5 \times 10^{19} \mathrm{~m}^{-3}$. Each measurement is an average over three shots and errors of $+/-7 \%$ can be considered when not indicated.

After about 30 hours of baking at temperatures less than $150{ }^{\circ} \mathrm{C}$ and 10 hours of GDC with Helium gas at currents of approximately $15 \mu \mathrm{A} / \mathrm{cm}^{2}$, the plasma current profile changed drastically from shot \#3036 to shot \#3330 (Fig. 2): the peak value decreased from $60 \mathrm{kA}$ to about $40 \mathrm{kA}$ and the pulse duration increased up to $12 \mathrm{~ms}$. Fig. 6 summarizes the results for the shot \# 3330. It can be observed the decreasing of the $\mathrm{H}_{\alpha}$ signal, a typical behavior of hot plasmas. It is also clear from Fig. $6 \mathrm{~A}$ and $6 \mathrm{~B}$ that the plasma column is centered approximately between $\mathrm{R}=25 \mathrm{~cm}$ and $\mathrm{R}=30 \mathrm{~cm}$. Exact values for the position of the center of the plasma column is difficult to be estimated due to the fact that the profiles were obtained with several shots. 
TABLE 2: Comparison between the present TS diagnostic (TS-1) and the proposed multipoint system (MTS).

\begin{tabular}{|l|l|l|l|l|l|l|}
\hline System & $\begin{array}{l}\text { Laser energy } \\
\text { required }\end{array}$ & Overall transmission & Collection NA & $\begin{array}{l}\text { Length of } \\
\text { observation }\end{array}$ & $\begin{array}{l}\text { Number of } \\
\text { scattered photons } \\
\text { in } \Omega\end{array}$ & $\begin{array}{l}\text { Number of detected } \\
\text { photons in each channel }\end{array}$ \\
\hline TS-1 & $4 \mathrm{~J}$ & $31 \%$ & 0.0833 & $15 \mathrm{~mm}$ & $9.1 \times 10^{5}$ & $\begin{array}{l}\mathrm{CH} 2: 2.2 \times 10^{4} \\
\mathrm{CH} 3: 5.5 \times 10^{4} \\
\mathrm{CH} 4: 1.9 \times 10^{4}\end{array}$ \\
\hline MTS & $7 \mathrm{~J}$ & $52 \%-8 \mathrm{~m}$ fiber & 0.07113 & $4 \mathrm{~mm}$ & $2.5 \times 10^{5}$ & $\begin{array}{l}\mathrm{CH} 2: 1.0 \times 10^{4}\left(8,5 \times 10^{3}\right) \\
\mathrm{CH} 3: 2.5 \times 10^{4}\left(2.1 \times 10^{4}\right) \\
\mathrm{CH} 4: 8.8 \times 10^{3}\left(7.2 \times 10^{3}\right)\end{array}$ \\
\hline
\end{tabular}
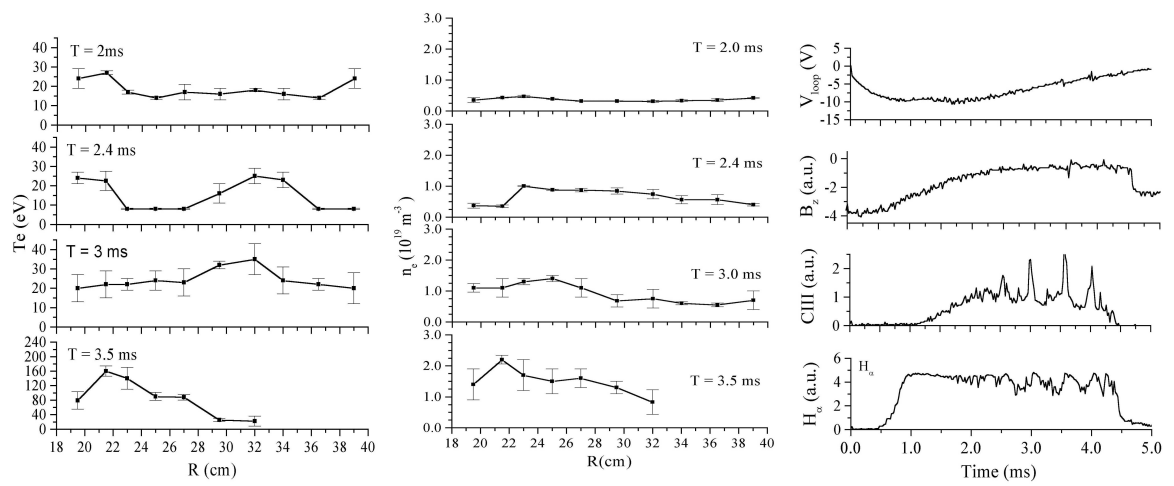

Figure 4. Radial electron temperature (A) and density (B) measurements (shots \#2461 to \#2551) for different times during discharges like \#2529 (see Fig. 2). (C) Typical signals of: Vloop - Loop voltage, $\mathrm{B}_{z}$ - Magnetic probe, CIII - Carbon III emission and H $\alpha$ - Hydrogen $\alpha$ emission.
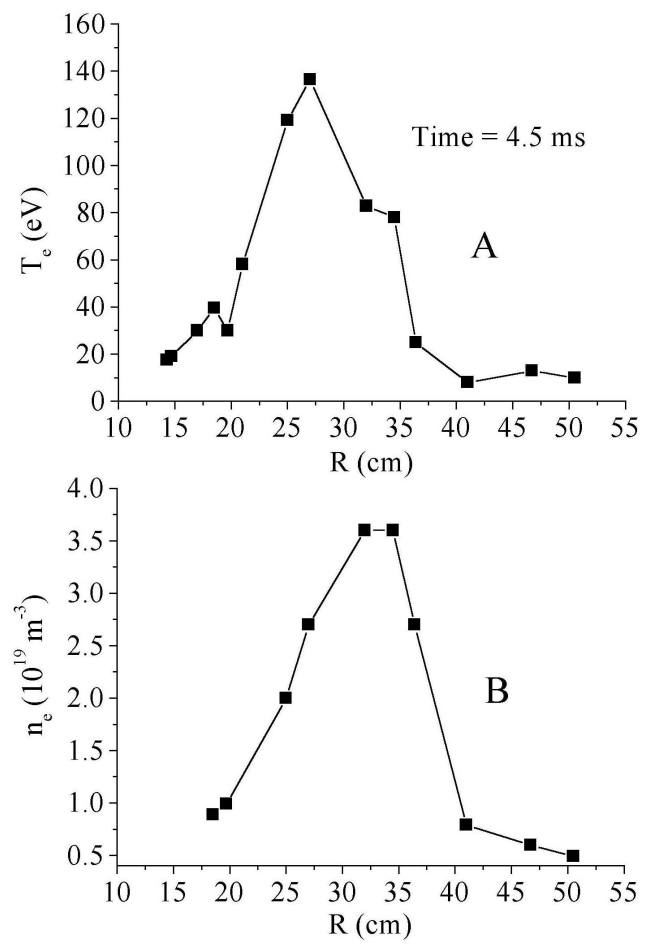

Figure 5. Electron temperature (A) and density (B) measurements, respectively, for the discharge as shot \#3036 (see Fig. 2) at $4.5 \mathrm{~ms}$.

\section{Fiber optic multiplex upgrade of the Thomson scattering}

A multipoint Thomson scattering (MTS) diagnostic based on the time-delay technique is being proposed to upgrade the present system. This MTS system consists in using several optical fibers of different lengths to transmit the light signals to the same polychromator [5][6]. The proposed system uses monofibers with a core diameter of $0.8 \mathrm{~mm}$ and $\mathrm{NA}=0.39$. These fibers present an average attenuation of $7 \mathrm{~dB} / \mathrm{km}$ in the spectral range from $694 \mathrm{~nm}$ to $880 \mathrm{~nm}$. Because the effective area of the detection system is limited to $7 \mathrm{~mm}^{2}$ it is not possible to introduce more than 10 fibers inside the present polychromator. Micro-lenses of $f=15 \mathrm{~mm}$ will be placed in front of each fiber to enlarge the observation region inside the plasma to $4 \mathrm{~mm}$. For this MTS setup the estimated lengths of the fibers are increased in steps of $14 \mathrm{~m}$ length difference. The first fiber has a length of $8 \mathrm{~m}$ and the last one (fiber number 10) of $134 \mathrm{~m}$. The overall transmission is estimated to be $52 \%$ for the first fiber and $42 \%$ for the last one, against the $31 \%$ for the present TS system. Table 2 summarizes the main parameters of the MTS system and also the present one (TS-1), assuming an electron temperature of $150 \mathrm{eV}$ and a density of $2 \times 10^{19} \mathrm{~m}^{-3}$. The number of scattered photons in the collection solid angle $(\Omega)$ was calculated by using Selden equations [7]. The number of photons that reach each channel was estimated taking into account the transmission of the optics and the polychromator spectral response. 

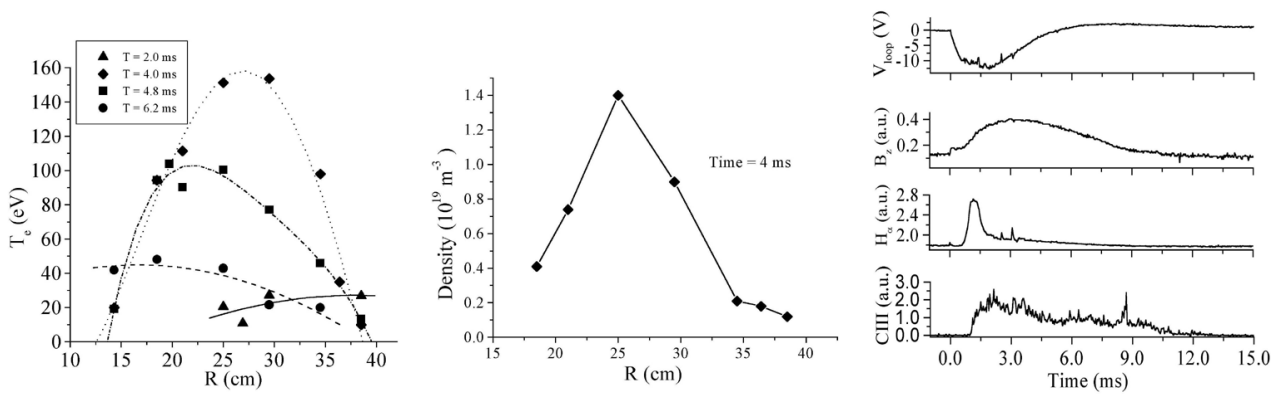

Figure 6. Electron temperature (A) and density (B) profiles after glow discharge cleaning as shot \#3330 in Fig. 2. Other diagnostics (C): Vloop - Loop voltage, $\mathrm{B}_{z}$ - Magnetic probe, $\mathrm{H} \alpha$ - Hydrogen $\alpha$ emission and CIII - Carbon III emission.
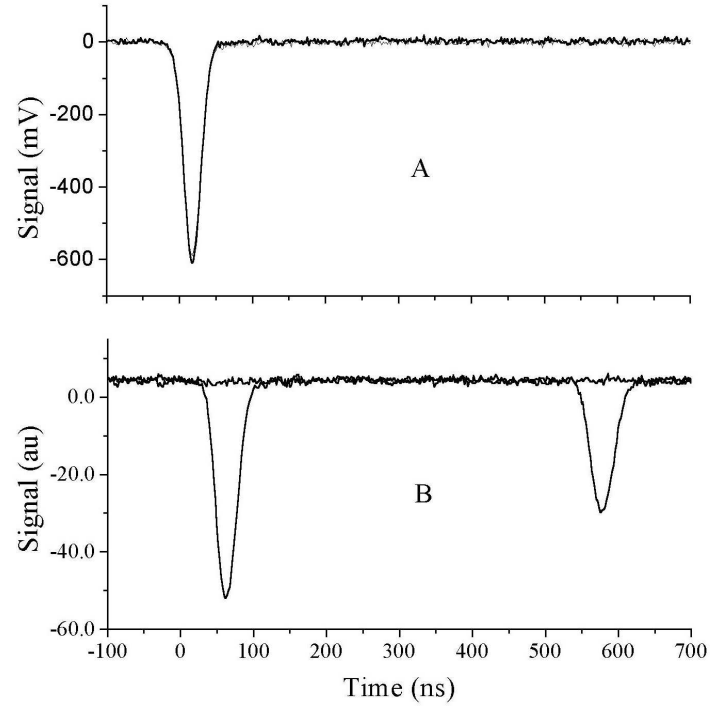

Figure 7. First tests with fibers for the MTS system. A) Ruby laser pulses. B) Normalized signals at the end of $8 \mathrm{~m}$ (left) and $112 \mathrm{~m}$ (right) fibers.

Figure 7 shows that the measured time delay between a fiber of $8 \mathrm{~m}$ and a fiber of $112 \mathrm{~m}$ is $512 \mathrm{~ns}$, that is very near to the calculations (504 ns). Although the absolute value of attenuation has not been measured, Fig. 7B shows that the peak value of the signal of the longest fiber is $61 \%$ of the shortest one, which is less than the estimated value of $84 \%$. This difference is due to the time dispersion of light signals that is proportional to the diameter and the length of the fiber. Note that, the transmission must be measured by the ratio of the areas under the signals, which is in agreement with the calculations. These tests were performed using the ruby laser beam attenuated by diffusers and filters.

\section{Conclusions}

The TS measurements show that the diagnostic was successfully implemented presenting a very stable alignment setup.
Other improvements in the flight tube and in the dump are under way to reduce even more the stray light levels. With the one-channel TS it is necessary more than one hundred shots to obtain the density and temperature profiles, which takes time and makes difficult the interpretation of the results. For these reasons a multipoint TS system using the multiplexed technique was planned. The MTS will allow simultaneous measurements of ten spatial points in a single ETE discharge using only one polychromator. The first tests with fibers to be used in the MTS showed good agreement with the calculations and tests with four channels are being prepared.

\section{Acknowledgements}

This work was partially supported by the Fundação de Amparo à Pesquisa do Estado de São Paulo (FAPESP). The participation of M. P. Alonso in this project has been supported by the Contract of Association between the European Atomic Energy Community and Instituto Superior Técnico.

\section{References}

[1] G. O. Ludwig, E. Del Bosco, J. G. Ferreira, et al, Braz. J. Phys. 33, 4 (2003).

[2] R. M. Oliveira, F. L. W. Barbosa, J. G. Ferreira, and C. S. Shibata, Fusion Eng. and Design 60, 403 (2002).

[3] R. M. Oliveira, M. Ueda, and W. A. Vilela, Braz. J. Phys. 32, 1 (2002).

[4] L. A. Berni, M. Ueda, E. Del Bosco, et al, Rev. Sci. Instrum. 74, 1200 (2003).

[5] M. P. Alonso, P. D. Wilcock, and C. A. F. Varandas, Rev. Sci. Instrum. 70, 783 (1999).

[6] M. P. Alonso, L. A. Berni, and E. Del Bosco, in 30th EPS Conference on Controlled Fusion and Plasma Physics, St. Petersburg, Russia, 2003.

[7] A. C. Selden, Physics Letters A79, 405 (1980). 